\title{
Decreased sensitivity of several anticancer drugs in TMEPAI knockout triple- negative breast cancer cells
}

Bantari Wisynu Kusuma Wardhani, ${ }^{1}$ Meidi Utami Puteri, ${ }^{2}$ Yukihide Watanabe, ${ }^{3}$ Melva Louisa, ${ }^{4}$ Rianto Setiabudy, ${ }^{4}$ Mitsuyasu Kato ${ }^{3}$

pISSN: 0853-1773 • elSSN: 2252-8083 https://doi.org/10.13181/mji.v28i2.2687 Med J Indones. 2019;28:110-5

Received: March 05, 2018

Accepted: May 16, 2019

\section{Authors' affiliations:}

${ }^{1}$ Doctoral Program in Biomedical Sciences, Faculty of Medicine, Universitas Indonesia, Jakarta, Indonesia ${ }^{2}$ Medical Science Master Program, Graduate School of Comprehensive Human Science, University of Tsukuba, Ibaraki, Japan ${ }^{3}$ Department of Experimental Pathology, Faculty of Medicine, University of Tsukuba, Ibaraki, Japan ${ }^{4}$ Department of Pharmacology and Therapeutics, Faculty of Medicine, Universitas Indonesia, Jakarta, Indonesia

\section{Corresponding author:}

Melva Louisa

Department of Pharmacology and Therapeutics, Faculty of Medicine, Universitas Indonesia, Jalan Salemba 6, Senen, Central Jakarta 10320, DKI Jakarta, Indonesia

Tel/Fax: +62-21-3920947

E-mail: melva.louisa@gmail.com

\begin{abstract}
BACKGROUND Transmembrane prostate androgen-induced protein (TMEPAI) was reported to be highly amplified in the majority of patients with triple-negative breast cancer (TNBC). TMEPAI is related to poorer prognosis, limited treatment options, and prone to drug resistance compared with other proteins. One of the established markers to determine cancer resistance to drugs is the increased expression levels of drug efflux transporters. However, the role of TMEPAI in cancer resistance to drugs has not been elucidated. This study was aimed to investigate whether TMEPAI participates in cancer resistance to drugs by regulating drug efflux transporters.
\end{abstract}

METHODS TMEPAI knockout (KO) cells were previously developed from a TNBC cell line, Hs578T (wild-type/WT), using a CRISPR-Cas9 system. The expression levels of drug efflux transporters were determined in Hs578T-KO and Hs578-WT by quantitative reverse transcriptase polymerase chain reaction. Cytotoxic concentration 50\% (CC50) of several anticancer drugs (doxorubicin, cisplatin, and paclitaxel) were determined in the two cell lines via 3-(4,5-dimethylthiazol-2-yl)-5-(3-carboxymethoxyphenyl)-2-(4sulfophenyl)-2H-tetrazolium assay.

RESULTS The results showed that the mRNA expression of P-glycoprotein (P-gp) and breast cancer resistance protein (BCRP) was significantly increased in Hs578T-KO compared with that in Hs578T-WT cells. CC50 of several anticancer drugs investigated (doxorubicin, paclitaxel, and cisplatin) in Hs578T-KO cells was higher than that in Hs678-WT.

CONCLUSIONS TMEPAI participated in the regulation of mRNA expression levels in drug efflux transporters (P-gp, BCRP, and multidrug resistance-associated protein 1). Further studies are necessary to confirm whether this finding might be dependent on the development of cancer cell sensitivity to anticancer agents.

KEYWORDS BCRP, MRP1, P-glycoprotein, TMEPAI, triple-negative breast cancer cell
Triple-negative breast cancer (TNBC) cells are characterized by the lack of the expression of estrogen receptor, progesterone receptor, and HER2/neu. TNBC has no targeted therapy yet. ${ }^{1}$ Even if it accounts for only $15-25 \%$ of total patients with breast cancer and $21 \%$ in 2011 in Indonesia, TNBC remains a major concern. ${ }^{2-4}$ It is responsible for more metastatic cases and breast cancer-related deaths in young women compared with other breast cancer subtypes. ${ }^{1}$ Moreover, treatment options using cytotoxic drugs for patients with TNBC are limited; patients eventually undergo resistance to anticancer agents, accounting for $90 \%$ treatment failure. One of the mechanisms in TNBC resistance to drugs is the overexpression of several drug-efflux transporters, such as multidrug resistance-associated protein 1 (MRP1), P-glycoprotein (P-gp), and breast cancer resistance protein $(B C R P) .5$ 
Transmembrane prostate androgen-induced protein (TMEPAI) was first reported as a novel androgen-regulated gene. ${ }^{6}$ TMEPAI is also known as a prostate transmembrane protein, androgen induced 1 , and solid tumor-associated gene $1 .{ }^{7}$ It is related to tumor relapse in the human prostate cancer xenograft model that is strongly androgendependent. ${ }^{6}$ Instead of androgen, TMEPAI is induced by epidermal growth factor in breast and ovarian cancer cell lines and in breast primary tumors ${ }^{8}$ and transforming growth factor- $\beta$ (TGF- $\beta$ ) in many cancer cell lines. ${ }^{9-11}$ In patients with TNBC, TMEPAl was reported to be highly amplified in $68.8 \%$ of patients and correlated with short survival time. ${ }^{2}$ Previous analysis of TMEPAl's prognostic significance suggested that high TMEPAI expression is correlated with poor prognosis with a hazard ratio of 1.88 ( $p$ $<0.05) .{ }^{12}$ Previous study of Wardhani et $\mathrm{al}^{13}$ showed that TMEPAI also plays a role in cell proliferation. TMEPAI was also reported as a converter for TGF- $\beta$ from a tumor suppressor in the early stages of carcinogenesis to a tumor promoter in advanced stages of carcinogenesis because of the inhibition of the TGF- $\beta$ canonical Smad pathway and the enhancement of the TGF- $\beta 1$-induced PI3K/AKT signaling pathway. ${ }^{5}$ Nevertheless, TMEPAI has been shown to contribute to TGF- $\beta 1$-induced epithelialmesenchymal transition (EMT) in lung cancer cells, and it further induces drug resistance in pancreatic and lung cancer. ${ }^{14,15}$ However, to date, the role of TMEPAI in cancer resistance to drugs has not been elucidated. This study was aimed to investigate whether TMEPAI might participate in drug resistance by regulating drug efflux transporters.

\section{METHODS}

\section{Cell culture}

This in vitro experimental study involved a TNBCcell line, Hs578T. The TNBC cell line Hs578T was obtained from Tsukuba University. Hs578T TMEPAI knockout (KO) cells were previously established from Hs578T wild-type (WT) using a CRISPR-Cas9 system. ${ }^{16}$ Both WT and KO Hs578T were cultured in Dulbecco's modified essential medium (Invitrogen) supplemented with $10 \%$ fetal bovine serum (Gibco), 10 $\mu \mathrm{g} / \mathrm{ml}$ insulin, 100 units $/ \mathrm{ml}$ penicillin $\mathrm{G}$, and $0.1 \mathrm{mg} / \mathrm{ml}$ streptomycin sulfate (Wako). Cells were maintained in a $5 \% \mathrm{CO}_{2}$ incubator at $37^{\circ} \mathrm{C}$. Cells were trypsinized at a confluency of about $80-90 \%$ and subjected to RNA isolation and quantitative reverse transcriptase polymerase chain reaction ( $q R T-P C R)$ analysis.

\section{qRT-PCR}

We isolated total RNA by using a Total RNA Mini Kit (Geneaid) from cultured cells, and RNA was converted to CDNA by using Transcriptor First Strand CDNA Synthesis Kit (Roche). RT-PCR was performed using FastStart Essential DNA Green (Roche). Primers used were purchased from Integrated DNA Technologies (IDT, Singapore) for $\beta$-actin, P-gp, $M R P 1$, and BCRP. The sequences for P-gp were Fwd: 5'-TTACATTCAGGTTTCATTTTGGTG-3'; P-gp Rev: 5'-TCCTGTCGCATTATAGCATGA-3'; the sequences for BCRP were Fwd 5'-TTCGGCTTGCAACAACTATG-3'; BCRP Rev: 5'-TCCAGACACACCACGGATAA-3'; and the sequences for MRP1 were Fwd 5'-ATGTCAACGTGGAATACCAGC-3' and Rev: 5'GAAGACTGAACTCCCTTCC-3'. $\beta$-actin was used as a housekeeping gene with the following sequences: $\beta$-actin Fwd: 5'-GCTGGAAGGTGGACAGCGA-3', $\beta$-actin Rev: 5'-GGCATCGTGATGGACTCCG-3'.

Approximately $20 \mu \mathrm{l}$ of the reaction was used in a 32-well plate on qRT-PCR Light Cycler Nano (Roche, USA). RT-PCR conditions comprised a threestep amplification process (45 cycles) in a specific annealing temperature of $52^{\circ} \mathrm{C}$ for P-gP and BCRP but $53^{\circ} \mathrm{C}$ for MRP1. The quantification cycle was analyzed by relative quantification using Livak method and described as normalized expression ratios of P-gp, $B C R P$, and MRP1 to $\beta$-actin.

\section{Cytotoxic concentration}

Cytotoxic concentration was measured based on cell viability via 3-(4,5-dimethylthiazol-2-yl)5-(3-carboxymethoxyphenyl)-2-(4-sulfophenyl)$2 \mathrm{H}$-tetrazolium (or MTS) assay by following the protocol in CellTiter 96 ${ }^{\circledR}$ Aqueous One Solution Cell Proliferation Assay. About $1 \times 10^{4}$ cells were seeded in a 96-microplate, and cells were grown until about $70 \%$ confluency. Subsequently, anticancer drugs were added 24 hours before performing MTS assay with cell confluence of at least 70\%. Doxorubicin, paclitaxel, and cisplatin were dissolved in dimethyl sulfoxide (DMSO) and diluted until the required concentrations were obtained. DMSO used in final concentrations did not exceed 0.01\%. DMSO was 
used as control in this experiment. Concentrations used for doxorubicin, paclitaxel, and cisplatin were from $0.5-50 \mu \mathrm{M}$. C 50 of the three drugs was calculated from the extrapolation from log-linear equations.

\section{Data analysis}

The differences between the two groups, Hs578T WT and Hs578T KO, was analyzed using Student's t-test. Significance was determined at $p<0.05$.

\section{RESULTS}

\section{Cell morphology}

The morphology of Hs578T WT and Hs578T KO cells is shown in Figure 1, a and b. No marked difference was observed in WT and KO cells.
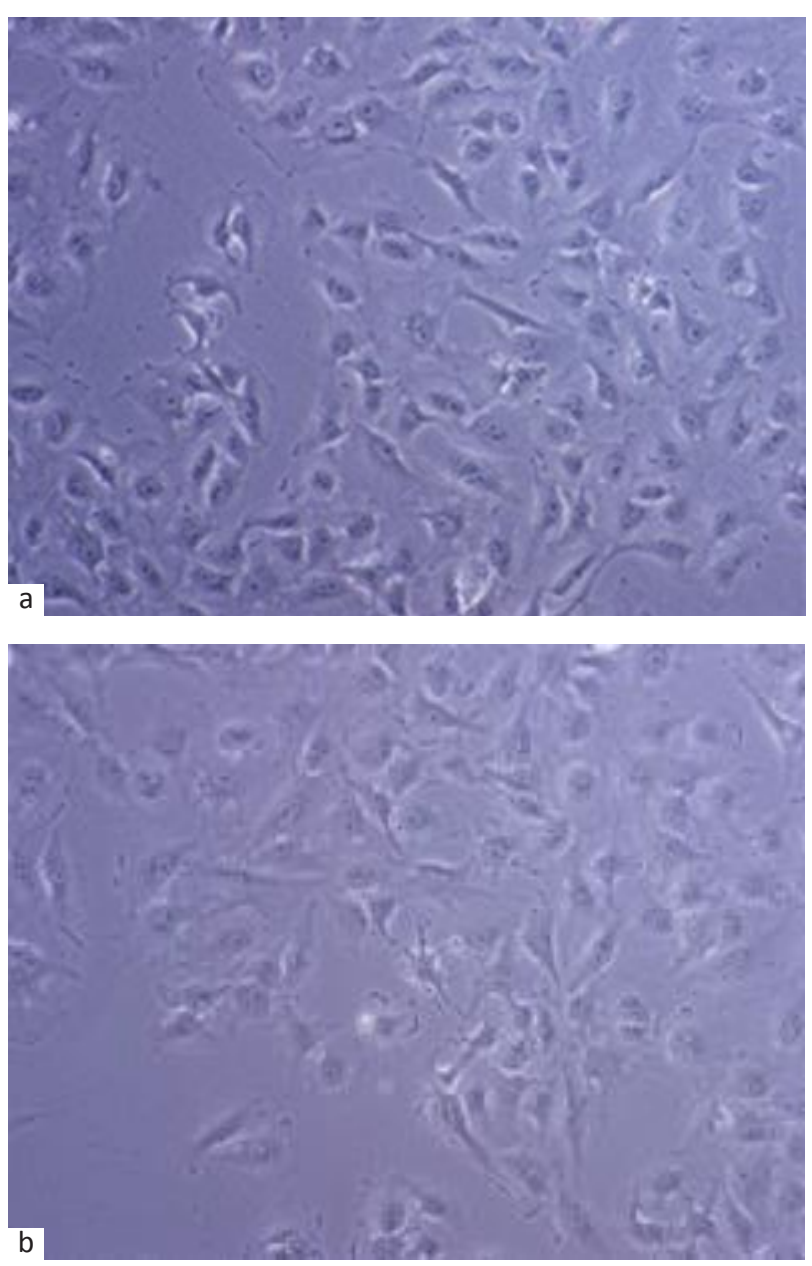

Figure 1. Morphology in KO cells was not remarkably different from that in WT cells: (a) TNBC cell line, Hs578T, which has TMEPAI WT (Hs578T WT); (b) TNBC cell line, Hs578T, which has TMEPAI KO (Hs578T KO) by CRISPR-Cas9 systems. $\mathrm{KO}=$ knockout; $\mathrm{WT}$ =wild-type; TNBC=triple-negative breast cancer; TMEPAI=transmembrane prostate androgen-induced protein
TMEPAI modulates mRNA expression of drug efflux transporters in Hs578KO cells

Our results showed that TMEPAI affected the drug efflux transporters, especially P-gP and BCRP (Figure 2). A slight increase in MRP1 was also found.
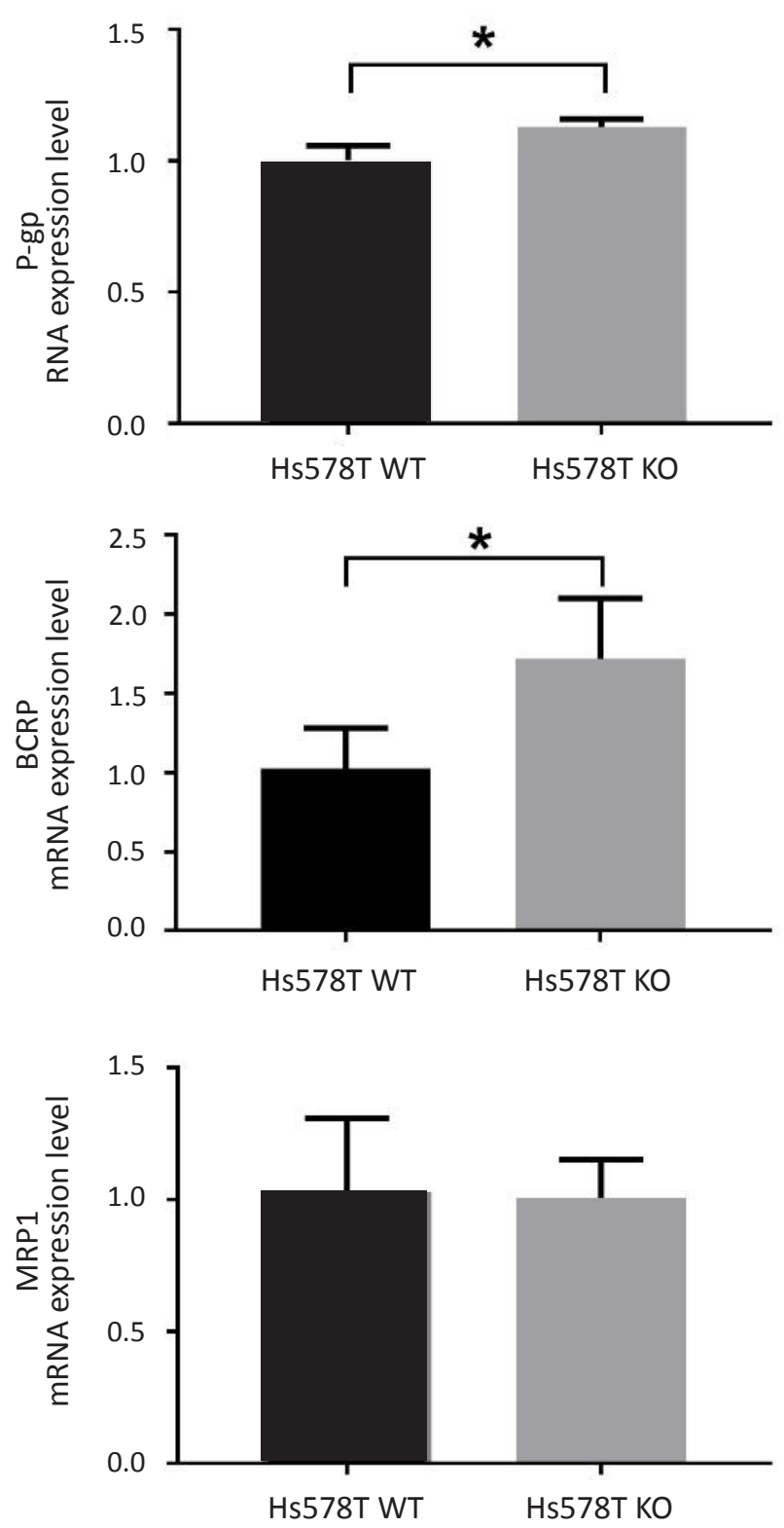

Figure 2. TMEPAI changed the mRNA expression level of drugefflux transporter: (a) P-gp mRNA expression level in Hs578T KO significantly increased compared with that in Hs578T-WT; (b) BCRP mRNA expression level in Hs578T KO significantly increased compared with that in Hs578T-WT; (c) MRP1 mRNA expression level increased in Hs578T-KO compared with that in Hs578T-WT. The mRNA expression was calculated as relative expression levels after normalization by $\beta$-actin as a housekeeping gene. All experiments were conducted in duplicate and repeated three times. Statistical analyses were performed using independent t-test. ${ }^{*} p<0.05$. TMEPAl=transmembrane prostate androgen-induced protein; $\mathrm{P}$-gP=P-glycoprotein; $\mathrm{KO}=$ knockout; WT=wild-type; $B C R P=$ breast cancer resistance protein; $M R P 1=$ multidrug resistance-associated protein 1 


\section{Decreased sensitivity to anticancer drugs in Hs578T KO cells}

In all the three most common anticancer drugs used in TNBC, a significant decrease in sensitivity to several anticancer drugs was noted (Figure 3). The increased sensitivity was most obvious in doxorubicin (2.8 times) and paclitaxel (2.3 times).
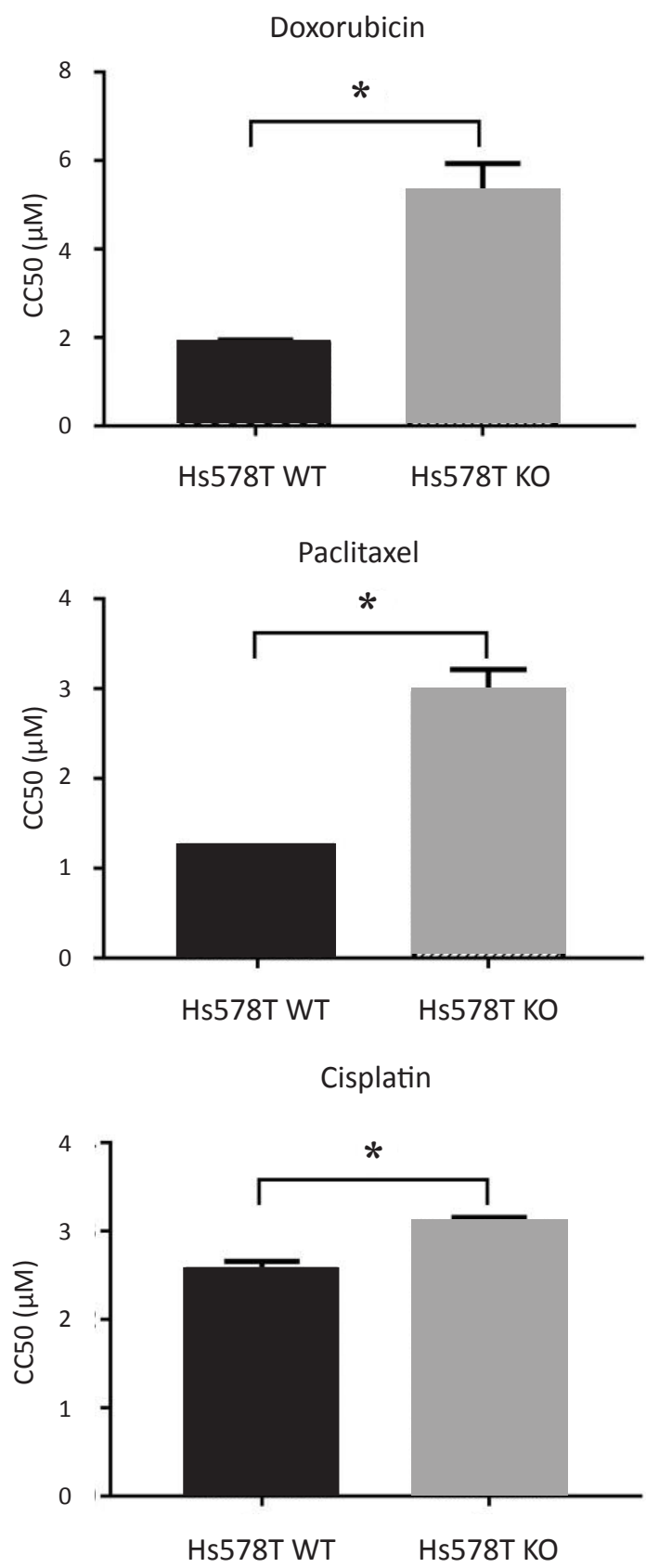

Figure 3. Decreased anticancer sensitivity in TMEPAI KO TNBC. Hs578T WT and KO were analyzed by MTS assay after 24 hours of anticancer treatment. All experiments were conducted in triplicate. Statistical analyses were performed using independent t-test. ${ }^{*} p<0.05 . \mathrm{CC}_{50}=$ cytotoxic concentration 50; TMEPAl=transmembrane prostate androgen-induced protein; $\mathrm{KO}=$ knockout; $\mathrm{TNBC}=$ triple-negative breast cancer; WT=wild-type

\section{DISCUSSION}

Given the high expression of TMEPAI in most patients with TNBC and its correlation with short survival and poor prognosis, we were interested to investigate it further. Regarding the molecular mechanism of TMEPAl, Watanabe et $\mathrm{al}^{11}$ and Singha et $\mathrm{al}^{2}$ reported that TMEPAI has tumorigenic activity in lung cancer and TNBC. The high expression of TMEPAI is also associated with oncogenic Snail expression. ${ }^{2}$ Therefore, these reports suggested that TMEPAI may be correlated with tumorigenesis and drug resistance. However, the molecular mechanisms of TMEPAI in tumorigenesis and drug resistance remain unclear. This paper was focused on anticancer drugs resistance.

In a preclinical study, Lehmann et $\mathrm{al}^{17}$ identified that human TNBC subtypes display gene expression patterns. Hs578T was reported as a mesenchymallike subtype suggested for preclinical studies on the TGF- $\beta$ pathway. ${ }^{17}$ This result was in accordance with TMEPAI research because of its involvement in the TGF- $\beta$ pathway. We then considered morphological alterations in drug resistance. Chen et al $^{18}$ reported morphological changes in doxorubicin-resistant cells compared with non-resistance cells using the BT20 cell line, an unclassified TNBC. They confirmed alterations in EMT markers, Snail and Twist, and morphological changes. ${ }^{18}$ In this model, no remarkable differences was observed in cell morphology between $\mathrm{KO}$ and WT (Figure 1, a and b). Singha et $\mathrm{al}^{2}$ reported that knockdown of TMEPAI TNBC cells demonstrates higher expression of Snail compared with WT. However, further experiments are necessary to determine whether the upregulation of EMT markers takes place in this models.

Currently, cytotoxic drugs are the backbone of TNBC treatments. Initially, the drugs show good efficacy, but cancer cells develop resistance to anticancer agents after a short period. ${ }^{5}$ Doxorubicin, paclitaxel, and cisplatin are commonly used in chemotherapy regimen. Doxorubicin kills cancer cells by intercalating into DNA and disrupting topoisomerase II-mediated DNA repair. Moreover, doxorubicin generates free radicals to harm cellular membranes. ${ }^{19}$ Paclitaxel is known to induce mitotic arrest, which leads to cell death. ${ }^{20}$ By contrast, cisplatin works by crosslinking with purine bases on DNA, interfering with the DNA repair mechanism, causing DNA damage, and promoting apoptosis in 
cancer cells. ${ }^{21}$ These anticancer drugs, which are used in TNBC, address DNA damage and cell cycles.

The overexpression of drug efflux transporters such as P-gp, BCRP, and MRP1 is one of the most common mechanisms in drug resistance. ${ }^{22,23}$ Doxorubicin, paclitaxel, and cisplatin are substrates for the three transporters, so increasing their expression will reduce the drug concentration in cancer cells. ${ }^{24}$ This finding is in accordance with this results. The increased expression of P-gp, BCRP, and MRP1 might lead to the efflux of anticancer agents from the cells. Hence, Hs578T KO demonstrated higher CC50 than WT cells.

This study investigated whether TMEPAI participates in drug resistance via the regulation of drug efflux transporters. This study results showed an enhancement in drug efflux transporters, followed by decreasing sensitivity of some anticancer agents. In line with this results, a previous study by Singha et $\mathrm{al}^{2}$ showed that TMEPAI inhibits TGF- $\beta$ growth suppression and enhances $\mathrm{PI} 3 \mathrm{~K} / \mathrm{Akt}$ signaling in TNBC. ${ }^{2}$ In addition, Bhola et $\mathrm{al}^{25}$ reported that inhibition of the TGF- $\beta$ pathways prevents drug resistance in cancer stem-like cells from TNBC. Li et $\mathrm{al}^{26}$ also showed that activating the $\mathrm{PI} 3 \mathrm{~K} / \mathrm{Akt}$ pathways promotes multidrug resistance for doxorubicin, paclitaxel, and cisplatin in cervical cancer cell line with increasing drug efflux transporter. Thus, activation of PI3K/Akt might be the underlying pathway responsible for the contribution of TMEPAI in drug resistance. However further studies need to verify this proposed pathway.

This study showed that the transporters were modulated in the TMEPAI KO cell line (Hs578T KO). The results demonstrated significant alterations in the mRNA expression levels of P-gp and BCRP after TMEPAI knocked out in the TNBC cell line (Figure 2, a and b). In accordance with these results, Hs578T KO showed decreasing sensitivity to anticancer drugs (CC50 increased; Figure 3). The clinical relevance and various expression levels of TMEPAI in patients with TNBC and cell lines were proven by Singha et al. ${ }^{2}$ They suggested that TMEPAI is an appropriate biomarker in distinguishing the staged development of TNBC. To complete those results, data on anticancer sensitivity were provided. TMEPAI is suitable for biomolecular targets to increase the sensitivity of patients with TNBC to anticancer drugs. Further experiments are warranted to elucidate the molecular mechanism of TMEPAI in anticancer sensitivity.
In conclusion, this results suggested that TMEPAI played a key role in the regulation of drug efflux transporters, particularly P-gp and BCRP. However, further mechanism-based studies are necessary to confirm this findings.

\section{Conflict of Interest}

Melva Louisa and Rianto Setiabudy are editorial board members but were not involved in the review or decision for the article.

\section{Acknowledgment \\ None.}

\section{Funding Sources}

This work was supported by grant of Publikasi Internasional Terindeks untuk Tugas Akhir Mahasiswa (PITTA) from Research Institution of Universitas Indonesia (Direktorat Riset dan Pengabdian Kepada Masyarakat, DRPM, Universitas Indonesia).

\section{REFERENCES}

1. Foulkes WD, Smith IE, Reis-Fielho JS. Triple negative breast cancer. N Eng J Med. 2010;363(20):1938-48.

2. Singha PK, Pandeswara S, Geng H, Lan R, Venkatachalam MA, Saikumar P. TGF- $\beta$ induced TMEPAI/PMEPA1 inhibits canonical Smad signaling through R-Smad sequestration and promotes non-canonical $\mathrm{PI} 3 \mathrm{~K} / \mathrm{Akt}$ signaling by reducing PTEN in triple negative breast cancer. Genes Cancer. 2014;5(9-10):320-36.

3. Krishnamurthy S, Poornima R, Challa VR, Goud YG. Triple negative breast cancer-our experience and review. Indian J Surg Oncol. 2012:3(1):12-6.

4. Ng CH, Pathy NB, Taib NA, Teh YC, Mun KS, Amiruddin A, et al. Comparison of breast cancer in Indonesia and Malaysia-a clinico-pathological study between Dharmais Cancer Center Jakarta and University Malaya Medical Center, Kuala Lumpur. Asian Pac J Cancer Prev. 2011;12(11):2943-6.

5. O'Reilly EA, Gubbins L, Sharma S, Tully R, Guang MH, WeinerGorzel $\mathrm{K}$, et al. The fate of chemoresistance in triple negative breast cancer (TNBC). BBA Clin. 2015;3:257-75.

6. Xu LL, Shanmugam N, Segawa T, Sesterhenn IA, McLeod DG, Moul JW, et al. A novel androgen-regulated gene, PMEPA1, located on chromosome 20q13 exhibits high level expression in prostate. Genomics. 2000;66(3):257-63.

7. National Center for Biotechnology Information. NCBI[Internet]. Bethesda MD USA: US National Library of Medicine; 2016 [cited 2016 Oct 23]. Available from: https://www.ncbi.nlm.nih.gov/ gene/56937.

8. Giannini G, Ambrosini MI, Di Marcotullio L, Cerignoli F, Zani M, MacKay AR, et al. EGF- and cell-cycle-regulated STAG1/ PMEPA1/ERG1.2 belongs to a conserved gene family and is overexpressed and amplified in breast and ovarian cancer. Mol Carcinog. 2003;38(4):188-200.

9. Brunschwig EB, Wilson K, Mack D, Dawson D, Lawrence E, Willson JK, et al. PMEPA1, a transforming growth factor-binduced marker of terminal colonocyte differentiation whose expression is maintained in primary and metastatic colon cancer. Cancer Res. 2003;63(7):1568-75.

10. Vo Nguyen TT, Watanabe $Y$, Shiba A, Noguchi M, Itoh S, Kato M. TMEPAI/PMEPA1 enhances tumorigenic activities in lung cancer cells. Cancer Sci. 2014;105(3):334-41.

11. Watanabe $\mathrm{Y}$, Itoh $\mathrm{S}$, Goto $\mathrm{T}$, Ohnishi E, Inamitsu M, Itoh F, et al. TMEPAI, a transmembrane TGF- $\beta$-inducible protein, sequesters Smad proteins from active participation in TGF- $\beta$ signaling. Mol Cell. 2010;37(1):123-34.

12. Györffy B, Lanczky A, Eklund AC, Denkert C, Budczies J, Li Q, et al. An online survival analysis tool to rapidly assess the effect of 
22,277 genes on breast cancer prognosis using microarray data of 1,809 patients. Breast Cancer Res Treat. 2010;123(3):725-31.

13. Wardhani BW, Puteri MU, Watanabe Y, Louisa M, Setiabudy R, Kato $M$. Knock-out transmembrane prostate androgen-induced protein gene suppressed triple-negative breast cancer cell proliferation. Med J Indones. 2017;26(3):178-82.

14. Hu Y, He K, Wang D, Yuan X, Liu Y, Ji H, et al. TMEPAI regulates EMT in lung cancer cells by modulating the ROS and IRS-1 signaling pathways. Carcinogenesis. 2013;34(8):1764-72.

15. Zheng X, Carstens JL, Kim J, Scheible M, Kaye J, Sugimoto H, et al. Epithelial-to-mesenchymal transition is dispensable for metastasis but induces chemoresistance in pancreatic cancer. Nature. 2015;527(7579):525-30.

16. Wardhani BW, Puteri MU, Watanabe $Y$, Louisa M, Setiabudy R, Kato M. TMEPAI genome editing in triple negative breast cancer cells. Med J Indones. 2017;26:14-8.

17. Lehmann BD, Bauer JA, Chen X, Sanders ME, Chakravarthy AB, Shyr $\mathrm{Y}$, et al. Identification of human tripple-negative breast cancer subtypes and preclinical models for selection of targeted therapies. J Clin Invest. 2011;121(7):2750-67.

18. Chen WC, Lai Y, Lin YC, Ma JW, Huang LF, Yang NS, et al. Curcumin suppresses doxorubicin-induced epithelialmesenchymal transition via the inhibition of TGF- $\beta$ and PI3K/Akt signaling pathways in triple-negative breast cancer cells. J Agric
Food Chem. 2013;61(48):11817-24

19. Thorn CF, Oshiro C, Marsh S, Hernandez-Boussard T, McLeod H, Klein TE, et al. Doxorubicin pathways: pharmacodynamics and adverse effects. Pharmacogenet Genomics. 2011;21(7):440-6.

20. Weaver BA. How taxol/paclitaxel kills cancer cells. Mol Biol Cell. 2014;25(18):2677-81.

21. Dasari S, Tchounwou PB. Cisplatin in cancer therapy: molecular mechanism of action. Eur J Pharmacol. 2014;740:364-78.

22. Longley DB, Johnston PG. Molecular mechanisms of drug resistance. J Pathol. 2005;205(2):275-92.

23. Oh KT, Baik HJ, Lee AH, Oh YT, Youn YS, Lee ES. The reversal of drug-resistance in tumor using a drug-carrying nanoparticular system. Int J Mol Sci. 2009;10(9):3776-92.

24. Silva R, Vilas-Boas V, Carmo H, Dinis-Oliveira RJ, Carvalho F, de Lourdes Bastos M, et al. Modulation of P-glycoprotein efflux pump: induction and activation as a therapeutic strategy. Pharmacol Ther. 2015;149:1-123.

25. Bhola NE, Balko JM, Dugger TC, Kuba MG, Sánchez V, Sanders $M$, et al. TGF- $\beta$ inhibition enhances chemotherapy action against triple-negative breast cancer. J Clin Invest. 2013;123(3):1348-58.

26. Li L, Wei XH, Pan YP, Li HC, Yang H, He QH, et al. LAPTM4B: a novel cancer-associated gene motivates multidrug resistance through efflux and activating PI3K/AKT signaling. Oncogene. 2010;29(43):5785-95. 